\title{
Spatial Correlation Analysis of Acoustic Impedance and Effective Porosity after Upscaling in Presalt Carbonate Reservoirs of the Santos Basin
}

Maria Luiza Cyrino Paiva*1, Fábio Júnior Damasceno Fernandes ${ }^{1}$, Igor Lima de Jesus ${ }^{1}$, Mariana Bittencourt Seabra Lebre $^{1}$, Fernando Vizeu ${ }^{1}$, Wagner Moreira Lupinacci ${ }^{1}$ and Antonio Fernando Menezes Freire ${ }^{1}$ 1 GIECAR-UFF

Copyright 2021, SBGf - Sociedade Brasileira de Geofísica.

This paper was prepared for presentation during the $17^{\text {th }}$ International Congress of the Brazilian Geophysical Society held in Rio de Janeiro, Brazil, $16-19$ August 2021.

Contents of this paper were reviewed by the Technical Committee of the $17^{\text {th }}$ International Congress of the Brazilian Geophysical Society and do not necessarily represent any position of the SBGf, its officers or members. Electronic reproduction or storage of any part of this paper for commercial purposes without the written consent of the Brazilian Geophysical Society is prohibited.

\begin{abstract}
Upscaling is an essential process in geological and geophysical studies, as it allows data on a well scale to be viewed on a larger scale without losing its main trends. This is a step that precedes important processes during reservoir characterization such as seismic inversion, facies modeling and porosity modeling. We analyzed how the upscaling affects the spatial correlation of acoustic impedance and effective porosity in carbonate reservoirs of the Barra Velha and Itapema formations, presalt of the Santos Basin. Three wells A, B and C were selected for the study and the methodology used comprises three main stages. The first is the computation of the effective porosity and acoustic impedance logs. In the second stage, the calculated logs were upscaled by applying the Backus Average with a sampling rate of 5 meters and a peak frequency of $100 \mathrm{~Hz}$. The third step was equivalent to the calculation and interpretation of the experimental variograms and the averages of the wells calculated preand post-upscaling. For each well the original and post-upscaling acoustic impedance and effective porosity logs were interpreted for the Barra Velha and Itapema formations separately, totaling 12 analyses of the upscaling effects. The exponential variogram model was the one that best fit the original data of acoustic impedance and effective porosity, except for effective porosity from well B in the Itapema Formation. In $72 \%$ of the cases, there was a change in the adjustment of the exponential model to the Gaussian model after the upscaling. This change was seen in all analyses in well $A$ and in half of the analyzes in wells $B$ and $C$. In all analyses, reductions in the experimental variogram sill were observed, reaching $60 \%$. This sill's behavior was expected, since after the upscaling the variance of the analyzed property tends to decrease. The experimental variogram range increased in $84 \%$ of cases. The post-upscaling variograms range increased 3 times, on average, reaching approximately 9 times. The best performance was the post-upscaling acoustic impedance log of well $C$ in the Barra Velha Formation, where the range reached 66 meters and the worst one was the post-upscaling effective porosity log of the well $B$ in the Itapema Formation with a range of approximately 11 meters. The increase in these variograms ranges is essential for future extrapolations from these well data. It was observed that the log averages after the upscaling were well preserved in both formations, and there was a general trend of decreasing averages that did not exceed $3 \%$. Thus, the upscaling applied reached the expectation of reducing the well data frequency preserving its main trends and being able to be used as input for next steps within a reservoir characterization workflow.
\end{abstract}

Keywords: spatial correlation, upscaling, reservoir characterization, porosity, acoustic impedance. 